\title{
What Do Genetics and Ecology Tell Us About the Design of Nature Reserves?
}

\author{
Michael E. Soulé \\ School of Natural Resources, University of Michigan, \\ Ann Arbor, MI 48109, USA \\ $\&$ \\ Daniel Simberloff \\ Department of Biological Science, Florida State University, \\ Tallahassee, FL 32306, USA
}

\begin{abstract}
The SLOSS (single large or several small) debate is no longer an issue in the discussion about the optimal size of nature reserves. The best way to estimate the minimum sizes of reserves may be a three-step process: (1) identify target or keystone species whose disappearance would significantly decrease the value or species diversity of the reserve; (2) determine the minimum number of individuals in a population needed to guarantee a high probability of survival for these species; (3) using known densities, estimate the area needed to sustain the minimum number. The forces that affect population viability and determine MVPS (minimum viable populations) are extremely complex. Thoughtful estimates of MVPs for many animal species are rarely lower than an effective size of a few hundred.

Attempts to save only common or smaller species in a community will usually be ill-fated because of the web of ecological relationships between species, including the importance of predation and herbivory in the maintenance of species diversity. Other topics discussed include the complementarity of conservation goals, the problematic function of corridors and the value of buffer zones.
\end{abstract}

Biol. Conserv. 0006-3207/86/\$03.50 C Elsevier Applied Science Publishers Ltd, England, 1986. Printed in Great Britain 


\section{WHAT ARE RESERVES FOR?}

Three goals are often given for setting aside a site as a nature reserve. First is the protection of particular species of interest, such as endangered or endemic species. Among American refuges established to protect particular species are those for the California condor Gymnogyps californianus, saguaro Carnegia gigantia, Kirtland's warbler Dendroica kirtlandii, and redwoods Sequoia sempervirens and $S$. gigantea. Second, as the science of ecology has matured, there has been increasing interest in preserving entire functioning communities. Finally, there is concern for preserving biotic diversity, per se, or the maximum number of species.

Usually, these goals are complementary aspects of the same overall principle of protecting nature; in practice most conservation programmes are also complementary. For example, in the southeastern US, one does not preserve red-cockaded woodpeckers Picoides borealis in the abstract. The reason the bird is endangered is that its habitat is rapidly disappearing-particularly the old, dying longleaf and loblolly pines that it uses for nesting. Consequently, one can preserve the woodpecker only by maintaining the sort of ecosystem in which these pines are allowed to reach the age when they begin to die. Such an ecosystem, in turn, will likely be quite similar to one that occupied the southeastern coastal plain before the arrival of Europeans, and will also likely contain a higher number of species than those with which humans have been replacing it.

There have been disputes within the conservation community, however, about whether species-oriented conservation projects might detract from goals of preserving entire, diverse ecosystems. Since economic and human resources are always limited, one can question whether efforts to preserve a particular species could endanger projects with broader objectives. In a world where choices are always required, is the particular habitat of a given species always the optimal choice for conservation?

\section{WHERE SHOULD NATURE RESERVES BE LOCATED?}

Cultural, political and economic factors often determine where reserves will be sited. In many instances, governmental or private conservation organisations are given the choice of either accepting a site for 
conservation management or allowing it to be put to some other use, and we do not have the luxury of saying that a different site would be better for conserving a particular species or community type. There may, in such instances, be valid reasons for rejecting the offer and letting a site be developed. For example, the management cost may be sufficiently large to detract from other conservation efforts, and the conservation value (in terms of the above three goals) may be negligible. As we discuss below, however, refuges that are admittedly suboptimal can be of great value, even aside from potential educational benefits.

Cultural. political and economic factors, then, constitute the first class of criteria for nature reserve location. There are several biological criteria. First, one should ask whether a particular site has optimal habitat for one or more species of special concern. The habitat requirements of some species are sufficiently narrow that there are very few choices. Second, one may seek areas where habitat and species diversity are greatest. Third, sites of maximum endemicity are of great value, particularly for the retention of biotic diversity. Finally, sites that are particularly secure for long-term conservation are desirable. The relationship of these criteria to the above motivations for setting aside reserves is apparent, but the last two criteria deserve further comment because their importance has not been universally appreciated.

Most of us intuitively grasp the value of rare or unique objects. Leaving aside the physiological basis of such aesthetic values, we are arguing that conservation ought sometimes to be based on uniqueness and endemicity, rather than on utilitarian considerations such as the possible future use of genetic resources. Though there is no objective way to determine how important endemicity is relative to other site criteria, it is possible to rank habitats as to endemicity. For example, Senanayake et al. (1977) found the value of upland forests to be about 50 times that of lowland forests in Sri Lanka.

Terborgh \& Winter (1983) have observed that some conventional criteria for siting reserves show little correspondence with points of maximum endemism, an especially serious problem in the Neotropics, where a very high fraction of species are endemics (Gentry, 1978). For example, Terborgh \& Winter found that South America harbours 440 endemic land birds with ranges less than $50000 \mathrm{~km}^{2}$. This constitutes about a fourth of the continent's avifauna, in contrast to North America, where the respective values are eight species and $2 \%$. They note that in Colombia and Ecuador, 'none of the crucial areas [for preserving 
endemics] are contained within the existing or projected park systems of either country'. Therefore, in some regions at least, the use of Holdridge life zones (Holdridge, 1967) or similar systems as a guide for the identification of potential reserve sites is clearly insufficient. Small reserves can be important for preserving endemic species of certain taxa (as we discuss below) but must be rigorously protected and may require intensive management (Terborgh, 1974, 1976; East, 1981a). This brings us to the issue of reserve integrity and long-term security.

Even large reserves may be threatened by disturbances in surrounding regions, because ecosystems are never completely isolated from one another. Biogeochemical cycles in particular are often regional or even global, so that developments outside a refuge may greatly affect its biota. No aquatic or terrestrial reserve in the northeastern United States or northern Europe, no matter how large and well managed, is immune to the effects of acid rain, which must be ameliorated by regional or national planning. Similarly, the Everglades in southern Florida are threatened by diversion of water that is occurring outside the park (Kushlan, 1979). Wherever possible, reserves should contain complete watersheds.

In summary, non-biological factors usually dictate the sites of large reserves. Except in the high latitudes, the opportunities for establishing large reserves will soon be past. Elsewhere, as more land is disturbed, small reserves will be established to protect the last refugia of endangered species and habitats. Such small 'garrison reserves' will often be expensive to protect and manage because of their high ratios of edge to area. For these reasons and others, traditional biogeographic criteria for the establishment of reserves must be complemented by those that are more sensitive to species diversity and to minimising disturbance within the reserves by development in the surrounding region.

\section{HOW SHOULD RESERVES BE DESIGNED?}

There are three separate questions: How big? How many? How arranged? In many places it is already too late to do much about design. The historical phase of establishing reserves is drawing to a close (Amazonia is the only major exception in the tropics), and, as discussed above, socioeconomic exigencies often preclude choice of size and shape. There is, nevertheless, much to be accomplished in establishing new reserves and in securing those that already exist. 
One important means of protecting refuges that already exist is by providing buffer zones to insulate them from many of the detrimental effects that unhindered human activity might produce. This need not always mean that the buffer zones themselves become parks, only that activities within them would be regulated so that they would impinge only minimally on the refuge. For example, the Government of India is considering a plan to establish seven Biosphere Reserves. The plan includes buffer zones that would encourage reafforestation, the restoration of degraded habitats and other programmes of eco-development (Anon., 1982). Local people would be trained as wardens and managers and would benefit economically from tourism in the core areas.

A recent debate, represented by the acronym SLOSS, has focused on the relative value of a Single Large or Several Small refuges, where the summed areas of the small reserves equal that of the large reserve. The history of this debate has been reviewed recently by Simberloff \& Abele (1982), and we hope here to put the issue finally to rest. In brief, the debate was initiated when Simberloff and Abele $(1976 a, b)$ criticised the contention of Wilson \& Willis (1975), Diamond \& May (1976), Diamond $(1975,1976)$ and Terborgh $(1975,1976)$ that the equilibrium theory of island biogeography dictates that single large refuges are generally preferable to groups of small ones. Their recommendations received wide attention and were incorporated into the World Conservation Strategy (IUCN, 1980).

Recent studies have resolved the primary issue. The equilibrium theory is neutral on the matter (Abele \& Connor, 1979; Gilpin \& Diamond, 1980; Higgs et al., 1981). Observational studies suggest that a few, dispersed, small sites usually contain at least as many species as does a single site of equal area. For example, Gilpin \& Diamond (1980) found that pairs of islands in the New Hebrides typically contain 5\% to $10 \%$ more species of lowland forest birds than do single islands with equal total areas. It is important to note, however, that this result has limited applicability in conservation practice. The reasons include:

(1) The possible slight advantage of several small sites is predicated on habitat being identical in the large and small sites. In nature, this requirement is never met, and habitat differences will almost certainly affect any real decision about which sites to preserve. That is, it is inconceivable that conservationists will ever be presented with the choice 
of preserving either site $\mathbf{A}$ or sites $\mathbf{B}$ and $\mathbf{C}$ (which together equal size $A$ in area), where habitat differences among the sites will not be sufficiently pronounced as to indicate a particular course of action.

(2) The only aspect of conservation that the result directly addresses is numbers of species present at a particular time, that is, the moment of demarcation. It does not refer to attempts to conserve particular species or entire functioning ecosystems. The reason is that most of the data, consisting of surveys of species present now on sites of different sizes, are not very informative about whether these species would persist on these same sites for long periods of time.

(3) Whatever the advantage of several small sites over single large ones for particular groups of species, the advantage would surely be sensitive to the degree of subdivision. For example, Gilpin \& Diamond (1980) found that ten small islands usually have fewer species than does a single large one. The particular point at which the small sites would become problematic depends on several factors, including the penetration of reserves by biotic and abiotic effects including wind, disease, exotic species and an increase in the densities of species that prefer 'edge' habitats (e.g. Janzen, 1983). It also depends on the minimum sizes of viable populations for the species of interest, a matter we discuss below.

(4) The effect is sensitive to the dispersal of the small sites. Obviously, two sites of $1 \mathrm{~km}^{2}$ each on different continents will have more species than a $2 \mathrm{~km}^{2}$ site on one continent, at least for most taxa. This is because most taxa on different continents have separate evolutionary histories, and most of their species are different. It is likely, however, that the same sort of effect would obtain over much shorter distances, for ecological rather than evolutionary reasons. Even within the same region, two separated sites are likely on average to differ more in habitat than are two contiguous sites, and so might be expected to be suitable for more species, so long as the areas were not too small (see below). Simberloff \& Gotelli (1984) and many others have hypothesised that it may be precisely this increased habitat diversity with dispersion that accounts for the common observation that a few small sites sometimes contain more species than single large ones, but the hypothesis has never been rigorously tested, or even examined with field data except by Kitchener et al. (1980).

(5) In some parts of the world, large areas have been set aside for conservation purposes because they have little or no agricultural, 
pastoral or other economic value (East, 1981a), whereas less marginal regions tend to have smaller reserves. For example, of the 15 largest protected areas in the USA listed by IUCN (1977), five are located in the arid west, three in Alaska and four in mountainous regions of the far west. In contrast, none of the 15 smallest protected areas in the USA are located in these agriculturally marginal regions. Therefore, the apparent diversity advantage of several small over single large sites may sometimes be exaggerated when the sampling units are existing refuges.

(6) The SLOSS effect, and the size range of refuges at which it breaks down, depends on the taxon. For example, plant species occupy sites of less than a square kilometre on narrow strata of the Green River shale of the Uinta Basin, apparently because of precise soil chemistry and drainage requirements. These include the columbine Aquilegia barnebyi, the beardtongue Penstemon grahamii and the milk-vetch Astragalus lutosus. The geological history of this part of Utah and Colorado suggests that these species have been narrowly restricted for many thousands of years, yet they have not been extinguished in spite of undoubted fluctuations in numbers. It is reasonable to expect that, if their habitat is rigorously protected, they will persist for millennia. Thus a group of very small sites may be quite adequate for the plants in some communities but would be useless for some of the animals (and thus for the system as a whole) because not one of them is large enough to support a population.

The SLOSS debate is, therefore, no longer an issue as regards numbers of species at the time reserves are founded. Virtually all conservation biologists agree that several small reserves can contain as many species as a single large one at the time of demarcation from their natural surroundings. The aspect of the SLOSS question that remains unanswered is the dynamics of species extinction after the reserves are set up and surrounded by habitat modified by human activities. The implications of size are great if rates of extinction depend on it.

To address this matter, we must consider the concept of minimum viable population (MVP). Nature reserves, like time capsules, are successful to the degree that their contents retain their integrity. They fail to the degree that their contents are destroyed. Reserves prevent extinctions by providing enough habitat and space. How much is enough? There are two answers. First, we must be sure that the dynamics of succession do not eliminate critical habitat within the landscape mosaic (Pickett \& Thompson, 1978; Foster, 1980; Gilbert, 1980). But 
even a reserve that is large enough to ensure the perennial persistence of all habitats and successional stages is not necessarily immune to extinctions. For example, a succession of managers might contrive to provide a large, dead tree as a nesting site for a pair of spotted owls Strix occidentalis or red-cockaded woodpeckers only to discover that, despite their good intentions, the birds always die out within a few generations. Obviously, one pair is not enough to ensure long-term viability.

This brings us to the second answer-we will have gone a long way towards answering the question of how large a reserve must be when we are able to determine the minimum number of individuals in a population needed to guarantee a high probability of survival. This is because a minimum number requires a minimum area. In investigating this question we are led to the study of those factors that determine the MVP and the distribution of the MVPs in space.

\section{POPULATION VIABILITY AS A CRITERION FOR RESERVE DESIGN}

Before setting out on a long and difficult journey we carefully pack those things we think will make the way safe and comfortable. For a species, the nature refuge is also a kind of journey, though it is a journey through time rather than space. It is a journey of millennia. The destination is survival. We humans are the travel agents; we try to anticipate the problems that might arise for our charges, and do our best to prepare them for any probable circumstance. As a general rule, everything needed by these passengers should be stocked in advance because the future is uncertain and there are no supplies along the way.

The metaphor of a journey suggests that we should ask if each species has some minimum (effective) population size $\left(\mathrm{N}_{\mathrm{e}}\right)$ for long-term survival. The relationship between the size of effective populations and the size of censused populations is a matter of genetic calculations that need not concern us here (see Frankel \& Soulé, 1981; Barrowclough \& Coats, in press), except to know that effective population size is almost always less than the number of mature individuals that one would simply count, and is often much less. Extinction is a question of risk; it is a probabilistic matter, and it is not crucial to our thesis that we be able to specify a 
particular magic number (e.g. 173) such that swift extinction is highly probable below, but not above, this number.

Rather, it is only necessary to accept that the expected time to extinction is shorter for small populations and that the time becomes very short (a matter of a few years or decades at most) at some size. If a refuge is so small that populations cannot exceed this size, then the species is doomed to quick extinction. Therefore, even if a refuge contains all of the habitats necessary for all species of concern, there will still be quick extinction of those species that cannot maintain an MVP.

Over geological time spans, all species are doomed to extinction (Raup \& Sepkoski, 1984). But the scale of 'background' extinction is very long compared to current anthropogenic rates. In any case, conservationists are concerned with preserving species for a few thousand years, not for an eternity. Similarly, even very large local populations occasionally go extinct even without human activity (MacArthur \& Wilson, 1967; Karr, 1982b; Ehrlich, 1983), but such normal 'turnover' is not usually of great concern because it is redressed by immigration from other populations that are still extant. As the earth is degraded, however, to a point where a large fraction of species are maintained only in reserves, there are few or even no other populations to redress an extinction-the local population at this point is the species, and normal turnover becomes species extinction. Thus, even when reserves are established, the smaller they are, the more quickly they will lose species, and a reserve so small that it approaches the MVPs of many species will soon be beset by many extinctions.

The forces that drive a species to extinction are exactly those forces that normally determine distribution and abundance. In other words, the MVP problem is no less complex than population biology itself, though it is focused on one particular boundary region in the abstract, multidimensional space of distribution and abundance in time. This is the boundary or threshold below which the probability of long-term survival is unacceptably low.

The forces and factors that have been considered (Terborgh, 1974; Shaffer, 1981; Soulé, 1983) can be classified conveniently, if arbitrarily, into two categories, extrinsic and intrinsic. Extrinsic forces include deleterious interactions with other species (increases in predation, competition, parasitism, disease or decreases in mutualistic interactions) and deleterious events or changes in habitat or the physical environment. 
Intrinsic factors include random variation in genetically based traits of the species and interactions of these traits with the environment. These include: (1) demographic stochasticity, which is random variation in sex ratio, in birth and death rates, and in certain abstractions of these traits, including the intrinsic rate of increase of the population (r); (2) social dysfunction or behaviours that become maladaptive at small population sizes; (3) genetic deterioration brought on by inbreeding, genetic drift and other factors. We will explain the impacts of some of these forces in greater detail.

\section{Demographic stochasticity}

This factor can contribute to fluctuations in population size, even driving populations to extinction. It is a far greater threat to small than to large populations; for example, the probability that all individuals in some generation will be male is higher the smaller the population. Simple models suggest that demographic stochasticity alone is unlikely to cause extinctions unless the population becomes very small, say, less than 20 (MacArthur \& Wilson, 1967; Richter-Dyn \& Goel, 1972).

It is obviously unrealistic to consider this factor in isolation from other factors that cause random or systematic changes in population size, but very few studies have attempted more comprehensive approaches. Leigh (1981) and Goodman (unpublished work) have provided some analytical solutions. Shaffer \& Samson (1985) have simulated the probable persistence of grizzly bears Ursus arctos in the Yellowstone National Park region, combining actual life history data and the effects of environmental variation on birth and death rates. In their simulation, the average time to extinction was 114 years for an environment with a carrying capacity of 50 animals. In 300 years 94 out of 100 such simulated populations would have failed. For this species, then, the model suggests that a census population of 50 is much too low to guarantee long-term survival in a refuge, even when other forces (genetics, disease, poaching, catastrophe) are ignored.

\section{Genetic deterioration}

There are three overlapping aspects of genetic deterioration. First are the immediate consequences of the erosion of heterozygosity. In outbreeding species that are heterozygous at many loci, more hetero- 
zygous individuals are in general more fit than less heterozygous ones. Many fitness criteria have been studied, including growth rates, scope for growth, viability, longevity, morphological symmetry, metabolic efficiency, frequency of disease and abnormality, and survival during stress (Schaal \& Levin, 1976; Botviniev et al., 1980; Zouros et al., 1980; Ballou \& Ralls, 1982; Beardmore, 1983; Leary et al., 1984; Samallow \& Soulé, 1983; Garton et al., 1984; Mitton \& Grant, 1984). The implications of these results for conservation are that any loss of heterozygosity for many species probably increases the mortality rate, especially during periods of stress or environmental change. Therefore, MVPs should be sufficiently large to maintain existing levels of heterozygosity.

Another aspect of genetic deterioration is inbreeding. Evidence is accumulating that most outbreeding species of animals avoid mating with close relatives, particularly siblings, even when they are raised apart (Packer, 1979; Pusey, 1980; Hoogland, 1982; Ballou \& Ralls, 1982). Many geneticists believe that the avoidance of inbreeding has resulted from natural selection. Inbreeding among normally outbreeding organisms usually results in a sharp decrease in fitness, especially fecundity and viability, and even small amounts of inbreeding have been shown to produce deleterious effects in wild species of primates (Ralls \& Ballou, 1982a), ungulates (Ballou \& Ralls, 1982) and small mammals (Ralls \& Ballou, 1982b). Such inbreeding depression can bring species to the brink of extinction. For example, in the endangered Brazilian golden lion tamarin Leontopithecus rosalia the high incidence of a genetic defect of the diaphragm is almost certainly caused by the high rate of inbreeding.

The third aspect of genetic deterioration is the long-term, evolutionary consequences of the erosion of genetic variation, the rate of which is roughly proportional to $1 / 2 \mathrm{~N}_{\mathrm{e}}$. It is an article of faith in evolutionary genetics that adaptability, the rate of evolution, can be limited by the availability of genetic variation. Several laboratory experiments demonstrate enhanced rates of evolution following an increase in genetic variability (Ayala, 1969; Chao et al., 1983). Notwithstanding the implications of such results, however, technical problems preclude experimental field tests establishing that limited genetic variability is a major factor in the extinction of a particular local population. In spite of these methodological difficulties, it is probable that very small populations are more vulnerable to environmental change than larger ones, because small populations will always have less genetic variation than large ones, everything else being equal. 
Conservationists must know the minimum effective size of a population for which deleterious inbreeding effects are balanced by natural selection against homozygotes for deleterious recessives. This size depends on the genetic load of the species, and some species (those with high rates of inbreeding in nature) may require only a few individuals for this balance. But for outbreeding animals, especially vertebrates, Franklin (1980) and Soule (1980) suggested that the experience of breeders leads to an estimate of about 50 breeding individuals.

In the long term, however, even an effective size of 50 cannot prevent the gradual loss of heterozygosity; such a population will lose most of its selectively neutral genetic variation in less than 100 generations (Senner, 1980). There is a growing consensus that a population should be large enough so that the input of new genetic variation from mutation balances the loss from genetic drift. An unresolved problem is that the population size at such a balance point depends critically on (1) the kinds of genetic variation being considered, (2) their respective mutation rates, and (3) the kinds of natural selection that act on these kinds of variation, all of which are difficult to define and estimate. This issue will be the focus of much research in coming years.

\section{Social dysfunction}

The third intrinsic force is maladaptive behaviour or social dysfunction. Such behaviour can lead to a precipitous decline in species that either forage in large groups or form large breeding congregations (Soulé, 1983). In the USA the extinctions of the Carolina parakeet, the passenger pigeon and the heath hen may have been facilitated by this force.

\section{Extrinsic factors}

Consideration of environmental or extrinsic factors usually dictates either an increase in MVP or an increase in the number of populations that must be maintained for long-term survival of the species or both. One such factor is disturbance. Many species use resources that exist only in temporary habitats. Natural disturbances, such as tree falls and fires, often initiate successional processes that produce these resources. The amount of suitable habitat, therefore, depends on the frequency and scale of such disturbances (Pickett \& Thompson, 1978; Foster, 
1980). In small reserves the rate of occurrence of such disturbances may be sufficiently low that critical habitat will occasionally disappear completely.

Contagious disease is another extrinsic force that can suddenly expunge a population or reduce it in size, enabling the intrinsic factors to weaken further or threaten the population (Frankel \& Soulé, 1981). The provision of more than one reserve sufficient for the MVP is therefore highly desirable, if not a design imperative.

Environmental variation and catastrophe are extrinsic forces that are on the same continuum, differing only in degree and frequency. Thunderstorms are just commoner and less severe than hurricanes. Events of this sort, which are relatively insignificant in a large reserve, can completely eliminate a particular habitat type in a small one. An entire small population can be extinguished by such events as fires, floods, mud slides, avalanches and wind storms. For example, Jones \& Diamond (1976) reported that a fire in 1959 on Santa Barbara Island off the coast of California temporarily eliminated nearly all the habitat of several bird species and, in combination with introduced rabbits, led to the extinction of the song sparrow Melospiza melodia. Similarly, a gale-driven fire destroyed nearly all of the habitat of the heath hen's Tympanuchus cupido cupido last redoubt in 1916, and this, combined with an unusually high density of the predatory goshawks Accipiter gentilis the next winter, drove the hen almost to extinction, an event that was completed by 1932 (Drury, 1974, and references therein). Therefore, persistence in a small reserve depends on whether a single population can survive such events as, say, the 300 -year flood or the 200-year drought, and whether such events so reduce the numbers that the intrinsic factors such as inbreeding can exacerbate fitness further. Obviously, the smaller the refuge, the greater the chance that a given event will be devastating over its entire area.

What, then, is the minimum size of a viable population? And how does this size translate into a design criterion? Clearly, there is no magic number. Not only is each species in each location a unique situation, but even if we could ignore taxonomic, genetic and ecological heterogeneity, the problem would still be difficult. A genetically derived MVP depends on assumptions about selection and on other parameters for which there are few data. The same could be said for analytical solutions that attempt to integrate demographic and environmental stochasticity (Leigh, 1975). To our knowledge, no one has even attempted the heroic 
task of producing a sophisticated model incorporating inbreeding effects with the other forces.

Thus, not only is there no magic number, there is no magic algorithm or protocol. Intuition, common sense and the judicious use of available data are still the state of the art. All these caveats accepted, MVPs on the order of a few hundred to several thousand genetically effective individuals are within the range that satisfy those scientists who have attempted to deal with real management situations (Schonewald-Cox, 1983; Salwasser et al., 1984). For large animals, such numbers translate into very large areas (Terborgh, 1974; Frankel \& Soulé, 1981). This means that in order to maintain the large predators in a community, and, with them, the critical regulatory roles that they perform, reserves the size of thousands of square kilometres are often necessary. On the other hand, small reserves and their remnant populations can often be salvaged, especially when a species is managed by a consortium of reserves. In addition, the co-operation of zoos in the captive breeding and enhancement of wild populations is becoming increasingly significant.

\section{CONCLUSIONS-A PLEA FOR BIGNESS AND MULTIPLICITY}

Nature reserves should be as large as possible, and there should be many of them. The question then becomes how large and how many. There is no general answer. For many species, it is likely that there must be vast areas, while for others, smaller sites may suffice so long as they are stringently protected and, in most instances, managed. If there is a target species, then the key criterion is habitat suitability. Suitability requires intensive study, especially in taxa that contain species with narrow habitat requirements. In other cases, however, the historical presence of the species (ideally, there would be long-term observations of the population that establish its continuous existence at densities with a typical mean and variance) may have to suffice as evidence of suitability, especially for large, generalist herbivores and carnivores.

The requirements of appropriate habitat and of sufficient knowledge of the habitat may seem too obvious to mention. Nevertheless, this issue often is ignored, sometimes because of the financial and logistical difficulties in gathering the information. We would emphasise, however, that the entire argument over SLOSS, MVPs and minimum areas may be rendered irrelevant where ecological data are unavailable.

Habitat requirements for particular species may not be an issue if 
there are no target species, or if the goal is to protect biotic diversity per se, as in centres of endemism. Even for such situations, however, it is prudent to assume that keystone species exist. Such species are likely to include trophically or reproductively important plants (Gilbert, 1980) as well as the largest carnivores and herbivores in the community. Once we have a good idea of the habitat requirements for real or probable target species, we can deal more efficiently with the matter of how large refuges must be, and how many of them will be necessary.

For two reasons, the smallest site occupied by a species is not necessarily the minimum feasible refuge, even if the habitat is optimal. First, the probability of extinction in the reserve might be unacceptably high, especially if the available habitat in and around the area has contracted in historical time because of habitat destruction and disturbance. On the other hand, it is conceivable that even smaller sites might be able to sustain a population (Simberloff \& Gotelli, 1984). In most cases, however, a detailed habitat study or historical records, combined with observed occupancy data, will provide evidence that persistence is unlikely in refuges below a certain size.

The matter of how many reserves must be established for a particular species is similarly difficult to deduce a priori, but historical records of population and even species extinctions brought about by many of the forces we have discussed above suggest that the prudent course would be to establish several refuges. Many 'contagious' agents of extinctiondisease, fire, introduced predators - can devastate or annihilate a species in a single reserve. For example, in 1984 alone 20 of the remaining 60 Javan rhinoceroses Rhinoceros sondiacus have died of a disease of unknown etiology (Anon., 1984).

The issue of contagion and quarantine is relevant to the desirability of corridors between reserves. The obvious virtues of corridors include facilitating gene flow and dispersal of individuals between components of the reserve system. This, in turn, decreases the rate of extinction of semiisolated groups (Brown \& Kodric-Brown, 1977), increases the effective size of the populations, and the recolonisation rate of extinct patches.

The benefits of corridors must be weighed against their costs, and against the possibility that the corridors will not work. Rivers and riparian habitats are mentioned most f́requently as sites for corridors. One problem is that many deep forest species may not venture into such habitats (Frankel \& Soulé, 1981). For example, the red tree vole Arborimus longicaudus and the California red-backed vole Clethrionomys 
californicus would probably avoid riparian corridors between patches of mature Douglas-fir Pseudotsuga menziesii forest. A more serious problem is that corridors increase the exposure of animals to humans, increasing the amount of poaching and their exposure to disease harboured in domesticated species. They also negate the quarantine advantage inherent in a system of isolated reserves.

In any case, political and economic exigencies often will prevent the establishment of corridors. In the absence of natural or of effective artificial corridors, management must deal with local extinctions and with deficits in gene flow by transferring individuals, where necessary, and by fouriding new colonies. In general, decisions about corridors must be considered on a case by case basis.

This discussion of size, number and connectivity of refuges is obviously germane if our motivation is to conserve particular species. As we stated at the outset, however, there are two other conservation goalsmaximising biotic diversity and maintaining functioning ecosystemsthat are at least as important. These goals may also demand large refuges, since they will necessitate sizes large enough to maintain the MVPs of all the species in the system. The most vulnerable species will often be either the large predators or else those species that are characteristically rare, even in the habitats to which they are adapted. Large mammals, especially predators, are among the rarest in most systems (e.g. Eisenberg, 1980; East, 1981a,b). East's studies have shown that many of the large savanna carnivores do not attain census numbers over 100 in many of the great African parks. In addition, large mammals are often jeopardised by poaching and disease.

One may question the necessity of designing and managing reserves for the benefit of relatively rare species. There are sound ecological reasons, however, why their maintenance is often necessary. The interrelationships of species within ecosystems may be subtle yet important. Mutualisms such as pollination abound, and many plant species constitute the necessary habitat for certain animals. It is part of the conventional ecological wisdom that predation (Paine, 1966; Connell, 1971; Karr, 1982a) and herbivory (Darwin, 1859; Harper, 1969; Lubchenco, 1978; Hay, 1981) help to maintain species diversity by preventing competitive exclusion among prey species. Thus it may not be possible to save only certain common species in a community, even if we wanted to. 
We are not saying that an entire community must be conserved if there is to be any conservation at all, especially in arid or cold regions. We are arguing, though, that saving the largest possible fraction of a community will usually facilitate saving any particular species. In addition, the ecological literature is rife with examples of recondite relationships among species that became apparent only when the decrease or disappearance of one has cascading detrimental effects on the others (Wilson \& Willis, 1975; Raven, 1976; Gilbert, 1980; Terborgh $\&$ Winter, 1980). So prudence also dictates that we attempt to save the largest possible fraction of a community.

As a rule, then, we suggest it would be wise to design refuges to conserve large fractions of a functioning community whenever possible. Though rigorous and intensive management may allow small sites to maintain populations of certain species, others will require much larger sites, and the larger the site, the larger the fractions of the community that one can expect to persist. The probabilistic nature of most of the forces that threaten small populations, as well as the difficulty in deducing very good estimates of MVPs, also imply that the prudent course is to establish large refuges wherever possible. Finally, the probabilistic aspects of extinction militate for multiple refuges, as does the contagious nature of some of the extrinsic forces.

We are aware that much of the argumentation in this paper is moot in many places and circumstances. Not only is the protection of nature perceived to be an elitist luxury in many nations, but even in the best of circumstances, public policies affecting conservation programmes can change overnight, subject to the inevitable succession of regimes, whether accompanied or not by violence. On the other hand, there are good reasons for suggesting scientifically based guidelines and standards for the practice of conservation. Without them, pro-conservation individuals and groups, in and out of governments, hardly have a leg to stand on when competing for land and resources with powerful elements arguing for appealing, short-term or ill-conceived development activities.

Recent events in conservation biology also suggest that guidelines, whether accepted or not by one's peers, provoke further research and interest, thus accelerating both the pace of research in the discipline and the reaching of consensus on controversial matters. It is in this spiritof faith in the scientific approach to conservation, of urgency in reaching consensus on vital issues - that we present this status report. 


\section{REFERENCES}

Abele, L. G. \& Connor, E. F. (1979). Application of island biogeography theory to reserve design: Making the right decision for the wrong reasons. In Proc. Conf. on Scientific Research in the National Parks, 1st, ed. by R. M. Linn, I, 89-94. Washington, DC, National Park Service, US Dep. Interior.

Anon. (1982). The state of India's environment 1982: A citizen's report. New Delhi, Centre for Science and Environment.

Anon. (1984). Notes and News. Oryx, 16, 299.

Ayala, F. J. (1969). Evolution of fitness, V. Rate of evolution in irradiated populations of Drosophila. Proc. natn. Acad. Sci. USA, 63, 790-3.

Ballou, J. \& Ralls, K. (1982). Inbreeding and juvenile mortality in small populations of ungulates: A detailed analysis. Biol. Conserv., 24, 239-72.

Barrowclough, G. F. \& Coats, S. L. (in press). The demography and population genetics of owls, with special reference to the conservation of the spotted owl (Strix occidentalis). In Ecology and management of the spotted owl in the Pacific Northwest, ed. by R. J. Gutiérrez and A. D. Carey. Portland, US Dep. Agric., Forest Service, Pacific NW Forest and Range Experiment Station.

Beardmore, J. A. (1983). Extinction, survival and genetic variation. In Genetics and conservation: $A$ reference for managing wild animal and plant populations, ed. by C. M. Schonewald-Cox, S. M. Chambers, B. MacBryde and W. L. Thomas, 125-51. Menlo Park, California, Benjamin/Cummings.

Botviniev, O. K., Kurbatova, O. L. \& Altukhov, Yu. P. (1980). Populationgenetic approach to the problem of non-specific biological resistance of the human organism. Genetica (USSR), 16, 1118-94.

Brown, J. H. \& Kodric-Brown, A. (1977). Turnover rates in insular biogeography: effect of immigration on extinction. Ecology, 58, 445-9.

Chao, L., Vargas, C., Spear, B. B. \& Cox, E. C. (1983). Transposable elements as mutator genes in evolution. Nature, Lond., 303, 633-5.

Connell, J. H. (1971). On the role of natural enemies in preventing competitive exclusion in some marine animals and in rain forests. In Dynamics of numbers in populations, Proc. of the Advanced Study Institute on Dynamics of Numbers in Populations, Oosterbeck, 1970, ed. by P. J. den Boer and G. R. Gradwell, 298-312. Wageningen, Centre for Agricultural Publishing and Documentation.

Darwin, C. (1859). The origin of species by means of natural selection. London, Murray.

Diamond, J. M. (1975). The island dilemma: Lessons of modern biogeographic studies for the design of natural reserves. Biol. Conserv., 7, 129-46.

Diamond, J. M. (1976). Island biogeography and conservation: Strategy and limitations. Science, N.Y., 193, 1027-9.

Diamond, J. M. \& May, R. M. (1976). Island biogeography and the design of natural reserves. In Theoretical ecology: Principles and applications, ed. by R. M. May, 163-86. Oxford, Blackwell.

Drury, W. (1974). Rare species. Biol. Conserv., 6, 162-9. 
East, R. (1981a). Species-area curves and populations of large mammals in African savanna reserves. Biol. Conserv., 21, 111-26.

East, R. $(1981 b)$. Area requirements and conservation status of large African mammals. Nyala, 7, 3-20.

Ehrlich, P. R. (1983). Genetics and the extinction of butterfly populations. In Genetics and conservation: $A$ reference for managing wild animals and plant populations, ed. by C. M. Schonewald-Cox, S. M. Chambers, B. MacBryde and W. L. Thomas, 152-63. Menlo Park, Calif., Benjamin/Cummings.

Eisenberg, J. F. (1980). The density and biomass of tropical mammals. In Conservation biology: An evolutionary ecological perspective, ed. by M. E. Soulé and B. A. Wilcox, 35-55. Sunderland, Mass., Sinauer Associates.

Foster, R. B. (1980). Heterogeneity and disturbance in tropical vegetation. In Conservation biology: An evolutionary-ecological perspective, ed. by M. E. Soulé and B. A. Wilcox, 75-92. Sunderland, Mass., Sinauer Associates.

Frankel, O. H. \& Soulé, M. E. (1981). Conservation and evolution. Cambridge, Cambridge University Press.

Franklin, I. A. (1980). Evolutionary change in small populations. In Conservation biology: An evolutionary-ecological perspective, ed. by M. E. Soulé and B. A. Wilcox, 135-49. Sunderland, Mass., Sinauer Associates.

Garton, D. W., Koehn, R. K. \& Scott, T. M. (1984). Multiple locus heterozygosity and the physiological energetics of growth in the coot clam, Mulinia lateralis, from a natural population. Genetics, 108, 445-55.

Gentry, A. H. (1978). Extinction and conservation of plant species in tropical America: a phytogeographical perspective. In Systematic botany, plant utilization and biosphere conservation, ed. by Inga Hedberg, 110-25. Stockholm, Almqvist \& Wiksell Int.

Gilbert, L. E. (1980). Food web organization and the conservation of neotropical diversity. In Conservation biology: An evolutionary ecological perspective, ed. by M. E. Soulé and B. A. Wilcox, 11-33. Sunderland, Mass., Sinauer Associates.

Gilpin, M. E. \& Diamond, J. M. (1980). Subdivision of nature reserves and the maintenance of species diversity. Nature, Lond., 285, 567-8.

Harper, J. L. (1969). The role of predation in vegetational diversity. In Diversity and stability in ecological systems, 48-61. Brookhaven Symp. Biol., 22.

Hay, M. E. (1981). Herbivory, algal distribution, and the maintenance of between-habitat diversity on a tropical fringing reef. Am. Nat., 118, 520-40.

Higgs, A. J. (1981). Island biogeography theory and nature reserve design. $J$. Biogeogr., 8, 117-24.

Holdridge, L. R. (1967). Life zone ecology. San José, Costa Rica, Tropical Science Center.

Hoogland, J. L. (1982). Prairie dogs avoid inbreeding. Science, N.Y., 82, 1639 41.

IUCN (1977). World directory of national parks and other protected areas. Morges, IUCN.

IUCN (1980). World conservation strategy: Living resource conservation for sustainable development. Gland, IUCN. 
Janzen, D. H. (1983). No park is an island: increase in interference from outside as park size decreases. Oikos, 41, 402-10.

Jones, H. L. \& Diamond, J. M. (1976). Short-time-base studies of turnover in breeding bird populations on the California Channel Islands. Condor, 78, $526-49$.

Karr, J. A. (1982a). Avian extinction on Barro Colorado Island, Panama: a reassessment. Am. Nat., 119, 220-39.

Karr, J. A. (1982b). Population variability and extinction in the avifauna of a tropical land bridge island. Ecology, 63, 1975-8.

Kitchener, D. J., Chapman, A., Dell, J., Muir, B. G. \& Palmer, M. (1980). Lizard assemblage and reserve size and structure in the Western Australian wheatbelt-some implications for conservation. Biol. Conserv., 17, 25-62.

Kushlan, J. A. (1979). Design and management of continental wildlife reserves: Lessons from the Everglades. Biol. Conserv., 15, 281-90.

Leary, R. F., Allendorf, F. W. \& Knudsen, K. L. (1984). Superior developmental stability of heterozygotes at enzyme loci in salmonid fishes. Am. Nat., 124, 540-51.

Leigh, E. G. Jr (1981). The average lifetime of a population in a varying environment. $J$. Theor. Biol., 90, 213-39.

Lubchenko, J. (1978). Plant species diversity in a marine intertidal community: importance of herbivore food preference and algal competitive abilities. $\mathrm{Am}$. Nat., 112, 23-39.

MacArthur, R. H. \& Wilson, E. O. (1967). The theory of island biogeography. Princeton, New Jersey, Princeton University Press.

Mitton, J. B. \& Grant, M. C. (1984). Associations among protein heterozygosity, growth rate and developmental homeostasis. Ann. Rev. Ecol. \& Syst., 15, 479-99.

Packer, C. (1979). Inter-troop transfer and inbreeding avoidance in Papio anubis. Anim. Behav., 27, 1-36.

Paine, R. T. (1966). Food web complexity and species diversity. Am. Nat., 100, 65-75.

Pickett, S. T. A. \& Thompson, J. N. (1978). Patch dynamics and the design of nature reserves. Biol. Conserv., 13, 27-37.

Pusey, A. E. (1980). Inbreeding avoidance in chimpanzees. Anim. Behav., 28, 543-52.

Ralls, K. \& Ballou, J. (1982a). Effects of inbreeding on infant mortality in captive primates. Int. J. Primatol., 3, 491-505.

Ralls, K. \& Ballou, J. (1982b). Effects of inbreeding on juvenile mortality in some small mammal species. Lab. Anim., 16, 159-66.

Raup, D. M. \& Sepkoski, J. J. (1984). Periodicity of extinctions in the geologic past. Proc. natn. Acad. Sci. USA, 81, 801-5.

Raven, P. H. (1976). Ethics and attitudes. In Conservation of threatened plants, ed. by J. B. Simmons et al., 155-79. New York, Plenum Press.

Richter-Dyn, N. \& Goel, N. S. (1972). On the extinction of a colonizing species. Theoret. Popul. Biol., 3, 406-33. 
Salwasser, H., Mealey, S. P. \& Johnson, K. (1984). Wildlife population viability: a question of risk. No. Am. Wildl. \& nat. Resour. Conf., 49.

Samallow, P. \& Soulé, M. E. (1983). A case of stress related heterozygote superiority in nature. Evolution, 37, 646-69.

Schaal, B. A. \& Levin, D. A. (1976). The demographic genetics of Liatris cylindracea Michx. (Compositae). Am. Nat., 110, 191-206.

Schonewald-Cox, C. S. (1983). Conclusions: Guidelines to management: A beginning attempt. In Genetics and conservation: A reference for managing wild animal and plant populations, ed. by C. M. Schonewald-Cox, S. M. Chambers, B. MacBryde and L. Thomas, 414-45. Menlo Park, Calif., Benjamin/Cummings.

Senanayake, F. R., Soulé, M. E. \& Senner, J. W. (1977). Habitat values and endemicity in the vanishing rain forests of Sri Lanka. Nature, Lond., 265, $351-4$.

Senner, J. W. (1980). Inbreeding depression and the survival of zoo populations. In Conservation biology: An ecological-evolutionary perspective, ed. by M. E. Soulé and B. A. Wilcox, 209-24. Sunderland, Mass., Sinauer Associates.

Shaffer, M. L. (1981). Minimum population sizes for species conservation. BioScience, 31, 131-4.

Shaffer, M. L. \& Samson, F. B. (1985). Population size and extinction: A note on determining critical population sizes. Am. nat., 125, 144-51.

Simberloff, D. S. \& Abele, L. G. (1976a). Island biogeography theory and conservation practice. Science, N.Y., 191, 285-6.

Simberloff, D. S. \& Abele, L. G. (1976b). Island biogeography and conservation: strategy and limitations. Science, N.Y., 193, 1032.

Simberloff, D. S. \& Abele, L. G. (1982). Refuge design and island biogeographic theory: effects of fragmentation. Am. Nat., 120, 41-50.

Simberloff, D. S. \& Gotelli, N. J. (1984). Effects of insularization on plant species richness in the prairie-forest ecotone. Biol. Conserv., 29, $27-46$.

Soulé, M. E. (1980). Thresholds for survival: maintaining fitness and evolutionary potential. In Conservation biology: An evolutionary-ecological perspective, ed. by M. E. Soulé and B. A. Wilcox, 151-69. Sunderland, Mass., Sinauer Associates.

Soulé, M. E. (1983). What do we really know about extinction. In Genetics and conservation: A reference for managing wild animal and plant populations, ed. by C. M. Schonewald-Cox, S. M. Chambers, B. McBryde and L. Thomas, 111-25. Menlo Park, Calif., Benjamin/Cummings.

Terborgh, J. (1974). Preservation of natural diversity: The problem of extinction prone species. BioScience, 24, 715-22.

Terborgh, J. (1975). Faunal equilibria and the design of wildlife preserves. In Tropical ecological systems: Trends in terrestrial and aquatic research, ed. by F. Golley and E. Medina, 369-80. New York, Springer.

Terborgh, J. (1976). Island biogeography and conservation: Strategy and limitations. Science, N.Y., 193, 1029-30.

Terborgh, J. \& Winter, B. (1980). Some causes of extinction. In Conservation 
biology: An evolutionary-ecological perspective, ed. by M. E. Soulé and B. A. Wilcox, 119-33, Sunderland, Mass., Sinauer Associates.

Terborgh, J. \& Winter, B. (1983). A method for siting parks and reserves with special reference to Colombia and Ecuador. Biol. Conserv., 27, 45-58.

Wilson, E. O. \& Willis, E. O. (1975). Applied biogeography. In Ecology and evolution of communities, ed. by M. L. Cody and J. M. Diamond, 522-34. Cambridge, Mass., Belknap Press of Harvard University.

Zouros, E., Singh, S. M. \& Miles, H. E. (1980). Growth rate in oysters: an overdominant phenotype and its possible explanations. Evolution, 34, 856-67. 